
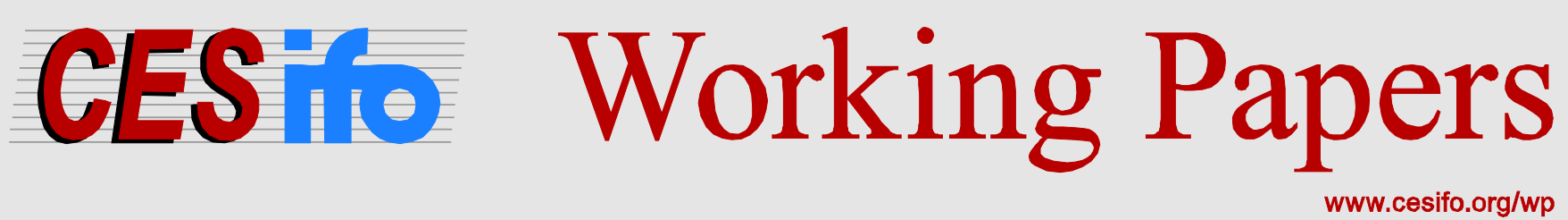

\title{
Diabetes and Labor Market Exits: Evidence from the Health \& Retirement Study (HRS)
}

\author{
Pinka Chatterji \\ Heesoo Joo \\ Kajal Lahiri
}

CESIFO WORKING PAPER NO. 5832

CATEGORY 4: LABOUR MARKETS

MARCH 2016

An electronic version of the paper may be downloaded

- from the SSRN website:

- from the RePEc website:

- from the CESifo website:

WwW.SSRN.com

www.RePEc.org

www.CESifo-group.org/wp 


\title{
Diabetes and Labor Market Exits: Evidence from the Health \& Retirement Study (HRS)
}

\begin{abstract}
The objective of this paper is to estimate the effect of diabetes on labor market exit using longitudinal data from the 1992-2010 Health and Retirement Study (HRS). We estimate a discrete time hazard model to test whether diabetes affects the hazard of leaving employment among individuals who were working for pay at the age of 55-56. Using a probit model, we also estimate the effect of having undiagnosed or poorly controlled diabetes on the probability of labor market exit two years later. Our results indicate that diabetes is associated with an increased hazard of exiting the labor market for both males, but not for females. This effect persists when we include controls for onset of other health conditions, two of which are documented complications due to diabetes (stroke and heart conditions). We also find diagnosed diabetes with medication use, regardless of whether it is under control, is associated with large negative effects on the likelihood of employment two years later.
\end{abstract}

JEL-Codes: J140, J160, J240, I120.

Keywords: hazard model, panel data, elderly health, undiagnosed diabetes, gender differential.

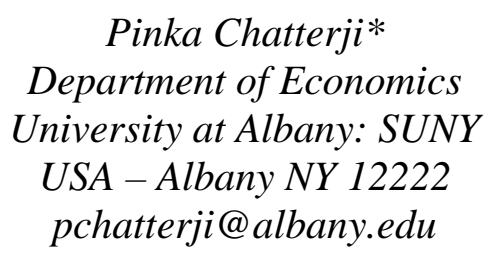

Heesoo Joo

Department of Economics

University at Albany: SUNY

USA - Albany NY 12222

hjoo@albany.edu
Kajal Lahiri

Department of Economics

University at Albany: SUNY

USA - Albany NY 12222

klahiri@albany.edu

*corresponding author

This research was supported by the National Institute on Minority Health and Health Disparities, National Institutes of Health (grant number 1 P20 MD003373). The content is solely the responsibility of the authors and does not represent the official views of the National Institute on Minority Health and Health Disparities or the National Institutes of Health. The HRS 2006 Biomarker data is sponsored by the National Institute on Aging (grant number NIA U01AG009740) and was conducted by the University of Michigan. 


\section{Introduction and Background}

As the US population ages, there is increasing concern among policymakers about the economic burden of chronic disease (Parekh \& Barton, 2010). In 2010, there were about 40.2 million people over age 65 in the US; by 2050 , the size of this group is projected to more than double to about 88.5 million people (Vincent \& Velkoff, 2010). Most individuals over age 65 have at least one chronic disease, and a significant proportion of the elderly live with multiple chronic diseases. ${ }^{1}$ Many studies document that individuals with chronic disease, particularly those with multiple conditions, are heavy users of health services, face high out-of-pocket spending for medical care, and are a driving force behind Medicare spending (Paez et al., 2012; Joyce et al. 2005; Thorpe, 2012; Vojta et al., 2012). Increasingly, researchers have documented that, in addition to these direct costs of chronic disease, there are likely to be important indirect costs. In particular, recent studies in economics show that health is an important determinant of individuals' decisions about employment, particularly as workers near retirement age (GarciaGomez et al., 2010; Jones et al., 2010; Miah \& Wilcox-Gok, 2007; Disney et al., 2006).

The objective of this paper is to estimate the effect of diabetes on exiting employment among older Americans using longitudinal data from the 1992-2010 Health and Retirement Study (HRS). We focus on diabetes because this disease is a leading cause of morbidity,

\footnotetext{
${ }^{1}$ Data from the 2008 Health \& Retirement Study (HRS), a nationally representative survey of older adults in the US, indicate that 92 percent of individuals aged 65 and over self-report at least one chronic health condition, and 17 percent self-report having four or more chronic diseases (Hung et al., 2011). The most common chronic diseases in the 2008 HRS population aged 65 and over are arthritis (66\%), hypertension (60\%), heart conditions (31\%), and diabetes (19\%) (Hung et al., 2011).
} 
disability, and mortality in the U.S (Sloan et al., 2008; Vojta et al., 2012), and the prevalence of diabetes is rising (Geiss et al., 2002; Engelgau et al., 2004). The Centers for Disease Control and Prevention (CDC), based on data from the National Health Interview Survey (NHIS), estimate that the age-adjusted prevalence of diagnosed diabetes increased from $3.7 \%$ in 1980 to $7.7 \%$ in 2008 (CDC, 2011).

Recent work indicates that diabetes has important effects on labor market outcomes. Most of these studies have been based on either cross-sectional data sets or on longitudinal data sets analyzed using cross-sectional data analytic methods. In many papers, the focus has been on addressing the potential endogeneity of diabetes status in the context of a model of labor market outcomes. For example, Latif (2009), using Canadian data, Minor (2011), using the 2006 NHIS, and Brown et al. (2005), using data on Mexican-Americans from the Border Epidemiologic Study on Aging, all examine the effect of diabetes on labor market outcomes using crosssectional data. They use instrumental variables methods to account for the potential endogeneity of diabetes with respect to labor market outcomes. The results show that diabetes has detrimental effects on labor market outcomes, but the results vary by gender.

In addition, Minor (2013), using data from the NLSY79, reports that Type II diabetes reduces the likelihood of being employed for males and females, and also reduces wages for males in some specifications. In this paper, the author has data on siblings, and thus can address the potential for unobserved family-specific heterogeneity by including family fixed effects in some models. Fletcher \& Richards (2012) use data from the National Longitudinal Study of Adolescent Health (Add Health) and find that self-reported diabetes among young adults (reported during Wave 4 of Add Health) is associated with worse contemporaneous educational and labor market outcomes. 
Two other recent papers use the HRS, as we do in the present study. Vijan et al. (2004) use data from the 1992-2000 HRS and find that having diabetes in 1992 is associated with increased risk of retirement, disability, and work absences between 1994 and 2000. This analysis, however, relies on standard OLS regression methods, and does not use methods that allow one to account for the dynamic nature of relationship under study. This study therefore cannot account for incident cases of diabetes that occur between 1994 and 2000, a critical time period during which many middle-aged and older individuals in the HRS are diagnosed with diabetes. Similarly, Tunceli et al. (2005) use data from two waves of the HRS and, using standard probit models, show that having diabetes in 1992 lowers the probability of working for pay in 1994 for both males and females.

In this paper, our main contribution is we estimate a discrete time hazard model in which we test whether diabetes is associated with the hazard of leaving employment among individuals who were working for pay at the age of 55-56. This approach has two important advantages in our context. First, we can account for duration dependence and for the effects of time-varying covariates - specifically, health shocks such as the onset of diabetes - on labor market exits. Second, we can take into account censoring of observations that occurs either because we don't observe the completion of a spell, or because of attrition due to dropping out of the HRS survey. The HRS includes self-reported diabetes information, as well as biomarkers for diabetes in the 2006 and 2008 surveys. Using this information, we can study both the effect of new onset of self-reported diabetes, as well as the effect of undiagnosed and poorly controlled diabetes, on labor market exits. This is a second contribution of this study to the existing literature on diabetes and labor market outcomes. 
Previous research primarily has relied on instrumental variables strategies to address the potential endogeneity of an individual's diabetes status. In our context, the main potential source of endogeneity is likely to be onset of other health conditions that occur at the same time as diabetes onset. To address this issue, we include a rich set of control variables in our models which capture the onset of many other chronic conditions that may be associated with diabetes onset. Also, our models include random effects to capture unobserved, time-invariant heterogeneity. Although we cannot rule out the possibility of confounding by other unmeasured, time-varying events that are correlated with diabetes onset, we have drawn on the extensive data available in the HRS to reduce the likelihood of this problem.

Our results based on self-reported diabetes information indicate that onset of diabetes is associated with an increased hazard of exiting the labor market for males, but not for females. Although we include onset of other health conditions in the models, two of which are documented complications due to diabetes (stroke and heart problems), and all of which directly affect labor market exit, the hazard of exit from the labor market associated with diabetes remains large and statistically significant for males. When we combine self-reported information with diabetes information from biomarkers, we find that both controlled and poorly controlled diabetes are associated with reductions in the likelihood of working for pay two years later. Lack of effective diabetes management, therefore, does not appear to be an important factor influencing older individuals' decisions about employment.

\section{Methods}

To estimate the effect of diabetes onset on labor market exit, we use a discrete time hazard model, an approach similar to that of Jones et al. (2010) and Garcia-Gomez et al. (2010). 
The discussion below follows Garcia-Gomez et al. (2010) closely. We start with a sample of HRS respondents who are working for pay at the age of 55-56. Over time, HRS respondents may stop working for pay due to retirement, unemployment, disability, or death, or they may be censored. Censored respondents are those who attrite from the sample for reasons other than death, and respondents who continue working continuously throughout the study period. We also consider respondents reaching age 67-68 to be censored since the determinants of labor force participation are likely to be distinct past the typical retirement age. We estimate the association between onset of diabetes and labor force exit for any reason - retirement, unemployment, disability, or death. ${ }^{2}$ We model an individual's duration in employment using a hazard function which represents an individual's conditional probability of leaving employment at time $t$, conditional on staying in employment until time t. Specifically, an individual i's discrete-time hazard of leaving employment, $h_{i}(t)$, is defined as:

$$
h_{i}(t)=P\left[T_{i}=t \mid T_{i} \geq t ; x_{i t}\right]
$$

where $T_{i}$ and $\mathrm{t}$ are discrete measures of time (i.e. integers representing survey waves) and $x_{i t}$ is a vector of covariates, which may be time-varying or time-invariant.

We define a dummy variable $y_{i t}=1$ if $\mathrm{t}=T_{i}$ and the individual $\mathrm{i}$ is not censored, and $y_{i t}=0$, otherwise. The log-likelihood function can be written as (Jenkins, 1995):

$$
\log L=\sum_{i=1}^{n} \sum_{k=1}^{t_{i}} y_{i t} \log \frac{h_{i}(k)}{1-h_{i}(k)}+\sum_{i=1}^{n} \sum_{k=1}^{t_{i}} \log \left(1-h_{i}(k)\right)
$$

Following Garcia-Gomez et al. (2010), Jones et al. (2010), and others, we specify a complementary log-log hazard rate. That is, the hazard function for each individual i for spell year $\mathrm{t}$ is written as follows:

\footnotetext{
${ }^{2}$ It would be useful to examine these categories separately, but we lack adequate sample size. In our sample, the number of respondents who exit to apply or receive SSI/DI is $n=121$ for males and $n=130$ for females.
} 


$$
h_{i}(t)=1-\exp \left(-\exp \left[c(t)+\gamma D_{i, t-1}+\beta^{\prime} x_{i t}+u_{i t}\right]\right)
$$

where $D_{i, t-1}$ is a dummy variable representing the individual's diabetes status in period t-1. In other words, $D_{i, t-1}=1$ if an individual i reported having been diagnosed with diabetes in period $\mathrm{t}-1$, and is 0 otherwise. In our main specifications, we use a lagged measure of diabetes to reduce the likelihood of reverse causality (work status affecting diabetes), but we also consider measures of current diabetes in alternative specifications. The expression $\mathrm{c}(\mathrm{t})$ is the baseline hazard function. We specify a non-parametric baseline hazard function $\mathrm{c}(\mathrm{t})$ as a step function, by using dummy variables to represent each time period during which individuals are at risk of exiting the labor market.

The discrete time hazard model directly addresses the right-censoring problem, but not the left-censoring problem. That is, the initial diabetes spell at $\mathrm{t}=0$ in the sample period has no known starting point. To deal with this issue, we use self-reported information in the HRS on the age of diabetes onset and include as covariates in all models control variables capturing "number of years since diabetes onset." This approach is similar to the approach used by GarciaGomez et al. (2010) to address the initial conditions problem.

Because unobserved heterogeneity is a potential problem, we further extend this model to the random effects complementary log-log model, which allows for $\operatorname{Corr}\left(u_{i t}, u_{i s}\right) \neq 0$ when $t \neq \mathrm{s}$. The model is based on the assumption that the unobserved heterogeneity is normally distributed with mean zero. ${ }^{3}$ Using a likelihood ratio test, we test the null hypothesis that

\footnotetext{
${ }^{3}$ As a sensitivity check, we also estimated a model in which the unobserved heterogeneity is assumed to be gamma distributed. This model does not include covariates other than the main diabetes measures due to convergence issues in the female sample. However, the findings were very similar to the same model estimated under the assumption that the unobserved heterogeneity was normally distributed. We fail to reject the null hypothesis of no heterogeneity in both the normally distributed and the gamma distributed models. Thus, the assumption of uncorrelated random effects is not critical in our context. These results are available upon request.
} 
heterogeneity is zero. We note that a limitation of this approach is that the random effects are assumed to be uncorrelated with the explanatory variables, including the measure of diabetes.

We also have information on diabetes biomarkers for HRS respondents in the 2006 and 2008 waves only (data discussed below), which allows us to consider more nuanced measures of diabetes, such as whether diabetes is controlled adequately. Since we only have two waves of data available for these models, we do not use a hazard model for estimation. In these models, the dependent variable is simply a binary indicator of whether or not the respondent is still working for pay two years after the diabetes biomarker information is collected. These models are estimated using standard probit models, and include controls for use of diabetes medication in addition to the full set of covariates included in the other models. The main analyses sample is limited to those who had diabetes biomarkers measured in 2006 or 2008, and had employment information in 2008 or 2010.

\section{Data}

Data for this study come from the 1992-2010 waves of the Health and Retirement Study (HRS), a biennial, nationally representative, longitudinal household survey initiated in 1992 with a sample of households in which the household heads were 51 to 61 years old. We use data from Version L of the RAND HRS. In 1992, the initial set of HRS cohorts, born between 1931 and 1941, were interviewed. The spouses of this cohort (who possibly were not born between 1931 and 1941) also are interviewed in 1992 and subsequent waves. In 1998, the HRS started to interview and followed longitudinally the War Baby (WB) cohort, born between 1942 and 1947. In 2004, the Early Baby Boomer (EBB) cohort, born between 1948 and 1953, started to be interviewed and followed longitudinally as well.

Analysis Sample: Individuals working for pay at age 55-56 
The analysis sample includes respondents: (1) who turn 55-56 years old during the time in which they participate in the ten waves of the 1992-2010 HRS and; (2) who are working for pay at 55-56 years old. We define $\mathrm{t}=0$ when an individual becomes $55-56$ years old. ${ }^{4}$ For instance, if an individual becomes 55-56 years old in the 1996 HRS interview (the $3^{\text {rd }}$ wave), the $3^{\text {rd }}$ wave is $t=0$ for that individual. For this individual, the maximum possible $t$ is 7 in the 2010 interview. Since the HRS is a biennial survey, if a respondent is 56 years old at the $3^{\text {rd }}$ wave and 54 years old at the $2^{\text {nd }}$ wave, we define the $3^{\text {rd }}$ wave as $t=0$ for the respondent. If a respondent is over 55-56 years old at her/his first interview, the respondent is excluded from our analysis sample. There are 11,510 respondents (4,982 males and 6,528 females) who turn 55-56 years old during their participation in the 1992-2010 HRS.

In Appendix Table 1, we show the total number of respondents who turn 55-56 years old at each HRS wave, and the number of respondents turning $55-56$ by their employment status. ${ }^{5}$ In other words, each row in Appendix Table 1 shows respondents who have the same $\mathrm{t}=0$ as the HRS interview wave shown in the first column. Among those who turn 55-56 years old during the time they are participating in the HRS, our sample of interest is limited to those who are working for pay at $\mathrm{t}=0$ since we want to investigate the effect of having diabetes on labor market exits. Among the 11,510 respondents who turn 55-56 years old during their HRS participation period, 8,179 individuals (3,946 males and 4,233 females) were working for pay at $\mathrm{t}=0$.

We follow this sample of working individuals until they are censored or until they exit the labor market. If $\mathrm{t}=\mathrm{t} 1$ is the first period in which an individual reports "not working for pay"

\footnotetext{
${ }^{4}$ To see whether our choice of age affected the findings, we also re-estimated all models based on a sample created based on respondents turning 53-54 years old during the HRS participation period. Results were similar to those presented here.

${ }^{5}$ The female sample is larger than the male sample because females in our sample tend to be the spouses of the heads of household, who tend to be males. Female spouses typically are younger than male spouses and thus are more likely to meet our criteria of turning 55-56 during HRS survey participation.
} 
or the individual is deceased, we define the individual as exiting the labor market at time $\mathrm{t} 1$

(Figure 1: Exit at t1). In our estimation, we capture the effect of diabetes on the transition from "working for pay" to "not working for pay" including death. We do not consider the possibility of a second spell for the same respondents, although it is possible that they exit the labor market and subsequently return to the labor market (Figure 1: Exit at t1 (2)). ${ }^{6}$ In our sample of 8,179 individuals who are working at age 55-56, we observe 3,552 exits due to transition of their status from "working for pay" to "not working for pay."

If an individual remains in the labor market by the $10^{\text {th }}$ wave (2010) and/or if an individual reaches age 67/68, s/he is censored. Among 8,179 respondents, 2,969 respondents (1,428 males, 1,541 females) are censored by remaining in the sample by the end of the survey period or by reaching 67/68 years old. In addition to remaining in the survey by the end of the survey period, we also include those who drop out of the survey and/or do not respond the survey in the censored group (Garcia-Gomez et al. 2010). In our sample, 1,658 respondents (881 males, 777 females) are censored due to dropping out or non-response.

\section{Measuring Diabetes}

In each HRS wave, respondents are asked about chronic illnesses, including diabetes. If a respondent is new in the wave, the respondent is asked "Has a doctor ever told you that you have [diabetes]?" If the respondent responds affirmatively, s/he is asked to give the year in which s/he was diagnosed. If a respondent participated in a prior HRS wave and reported diabetes in the last interview, the interviewer reminds the respondent of his/her previous report,

\footnotetext{
${ }^{6}$ Because we do not consider re-entries and re-exits after the first labor market exit, the labor market exit may represent a permanent or temporary exit, or the start of a period of reduced labor market attachment. In our analysis sample, 578 respondents (11.6\%) experienced re-employment once, and 34 (0.68\%) experienced re-employment more than once. As a sensitivity check, we re-estimated the models including respondents who exited and the reentered as censored. The findings are similar to those shown in the paper. These findings are available upon request.
} 
and notes if the respondent disputes the prior report of illness. If not, the interviewer moves to the next question.

Based on this self-reported information, we create two lagged measures of diagnosed diabetes, Diabetes with medication ( $\mathrm{t}-1)$ and Diabetes without medication (t-1), using diabetes information measured at the prior HRS wave at $\mathrm{t}-1$. We allow for respondents to change their diabetes status in either direction (from 0 to 1 , or from 1 to 0 ). Diabetes with medication (t-1) is 1 when an individual reported oral medication and/or insulin shots for controlling diabetes at $t-1$ and otherwise 0 . Diabetes without medication (t-1) is 1 if an individual did not report any oral medication nor insulin shots at $\mathrm{t}-1$, but reports having diabetes (Table 1). We consider diabetes medication usage as an indication of more severe or advanced disease.

There are two reasons we prefer to use lagged indicators of diabetes. First, diabetes information is not available at $\mathrm{t}=\mathrm{T}$ for those who are censored due to drop out or non-response, and for those who exit due to death. This is true not only for diabetes status but also for all time varying variables. If an individual reports having diagnosed diabetes at $\mathrm{t}-1$, it may be reasonable to assume that the individual has diabetes at $\mathrm{t}$, even though $\mathrm{s} / \mathrm{he}$ did not respond at $\mathrm{t}$, because of the chronic nature of diabetes. If an individual did not report diabetes at $\mathrm{t}-1$, however, we cannot determine whether an individual had onset of diabetes by time t or not.

Next, there is the reverse causality issue. We are interested in the effect of diabetes on the risk of labor market exit. However, if we use diabetes status at $\mathrm{t}$ as an independent variable to explain labor market status at $\mathrm{t}$, it is unclear whether diabetes led to the labor market exit or whether the diabetes is diagnosed after the exit from labor market. Although we focus on models which include lagged measures of diabetes, for comparison purposes, we also estimate a set of models which include current diabetes measures. In these models, we assume that diabetes 
status at time period $t$ is the same as it was in time period $t-1$ for respondents who are censored due to drop out or non-response, and for those who exit due to death at time period t.

Our models also include as a covariate the number of years since the respondent was first diagnosed with diabetes (Table 1). We consider both a continuous variable measuring number of years the respondent has had diabetes, as well as a set of dummy variables indicating respondents had diabetes for 1-2, 3-5, 6-10, 11-20 and 21 or more years. As discussed above, conditioning on 'the number of years since first diagnosed with diabetes' in the duration model specifications addresses the problem of left-censoring. Also, longer cumulative exposure to diabetes indicates a higher risk of complications (Zhuo et al. 2013).

One limitation of all the diabetes measures discussed up to this point is that they are selfreported - thus, undiagnosed cases are not included, and there also is no objective way to measure how well the disease is under control. ${ }^{7}$ To take into account undiagnosed cases of diabetes and consider severity in a more objective way, we also consider the effect of the respondent's A1C level, a diabetes biomarker, on labor market exit. Information is available on A1C levels for HRS respondents who participated in the survey in 2006 and 2008. In 2006, half of HRS respondents were randomly selected to participate in a blood draw which provided A1C measures. In 2008, the remaining half of randomly selected respondents who were not assigned to a blood draw in 2006 provided A1C measures. The A1C level is a measure of the average glucose level in the respondent's blood over the past 2-3 months. Following guidelines from the American Diabetic Association, we consider an A1C of higher than 6.5 percent to be an indicator of diabetes (Buell et al. 2007; Ginde et al. 2008), while a an A1C between 5.7 and 6.5 is

\footnotetext{
${ }^{7}$ Self-reported information on the degree to which diabetes is "under control" is available for the 1996 2010 HRS, but more than $90 \%$ of respondents with diabetes self-reported that the disease was "under control." Also, the HRS 1992 and 1994 did not include the "under control" information.
} 
considered to be an indicator of pre-diabetes. We also consider a continuous measure of A1C in the models, with a higher A1C measure indicating that the glucose level in the body is less controlled (worse severity). ${ }^{8}$

In Appendix Table 2, we show the number of respondents with undiagnosed diabetes, and the numbers for whom diabetes is controlled vs. uncontrolled, based on combined information from self-reports of diabetes and the biomarker data. We consider diabetes to be uncontrolled if a respondent self-reports having diabetes, but the A1C level is 6.5 or higher. We consider diabetes to be undiagnosed if a person does not report having diabetes but has an AIC level 6.5 or higher. Note that the sample used for this analysis is our main analysis sample limited to those had A1C measures in 2006 or 2008. From Appendix Table 2, one can see that the numbers of respondents in certain categories become small. By combining some of these categories, however, and by combining the male and female samples, we can explore the effects of measures of uncontrolled and controlled diabetes on labor market exit. Results are discussed below.

In Appendix Table 3, we show diabetes status by time period $t$ for the male and female analysis samples. The analysis samples include 3,946 males and 4,233 females who turn 55-56 years old during their HRS participation period and were working for pay at $\mathrm{t}=0$, but the samples are further limited to those respondents who had available information on all covariates used in the analysis. Appendix Table 3 shows that as the HRS respondents age, the prevalence of diabetes rises steadily, particularly for males. At $t=0$, when respondents are 55-56 years old, the

\footnotetext{
${ }^{8}$ Unfortunately, the HRS does not have information regarding Type I vs. Type II diabetes. Type I diabetes accounts for 5-10 percent of cases worldwide, and it is typically diagnosed in childhood or adulthood (Maahs et al., 2010). The HRS has information on the age of diabetes onset among those respondents reporting diabetes. Less than $1 \%$ of our analysis sample with diabetes reported having age of onset prior to 20 years old. This information gives us confidence that we are mainly capturing the effects of Type II diabetes on labor market exits.
} 
prevalence of diabetes among males is about $10 \%$; for males, it rises to $20 \%$ by $t=6$. The rise for females is not as dramatic - from $t=0$ to $t=6$, the prevalence of diabetes increases from about $8 \%$ to about $14 \%$ in our sample.

In addition to the diabetes variables, all models include controls for race/ethnicity, level of education, marital status, cohort dummies, and dummy variables for industry. The indicator of "married" is interacted with spousal work status and education. The models are analyzed by gender. In some specifications, we also include in the models lagged indicators for other serious health conditions which can affect labor market exits - stroke, heart problems, hypertension, cancer, arthritis, psychiatric problems, lung disease, and body mass index (BMI) (Table 1). Our final analytic sample includes 2,570 males and 2,756 females. The average number of periods respondents stay in the sample is 3.6 waves for male and 3.4 waves for females, when each HRS wave represents about 2 years.

\section{Results}

Tables 2 and 3 summarize results from the random effects discrete time hazard model, which is estimated separately for males (Table 2) and females (Table 3). Columns 1a of Table 2 (males) and Column 1b of Table 3 (females) show results from a model which estimates the effect of onset of self-reported diabetes on the hazard of labor market exit. These models include a continuous measure of the number of years since diabetes diagnosis as a covariate, as well as a set of socio-demographic and job-related controls (see notes to Tables 2 and 3 for full listing of covariates). For males, we observe that the hazard of labor market exit is about 1.4 times greater for those who have been diagnosed with diabetes and were using medication in the last HRS wave, compared with those who did not have diagnosed diabetes with medication at this time 
(Column 1a, Table 2). This association is statistically significant at the 0.05 level. Among males, there is no statistically significant association between onset of diabetes without medication and hazard of labor market exit, although the estimated hazard ratio is 1.26 (Column 1a, Table 2).

Among females, onset of diabetes at t-1 with medication is associated with an increase in the hazard of labor market exit by about 13\% (hazard ratio: 1.13) (Column 1b, Table 3), but this association is not statistically significant. Similarly, there is no statistically significant association between onset of diabetes without medication at $\mathrm{t}-1$ and labor market exit among females (Column 1b, Table 3).

Columns 2a-b in Tables 2-3 show findings from the same models as those shown in Columns 1a-b except that these models include other lagged chronic health conditions as an additional set of control variables, since onset of diabetes may be associated with the onset of other chronic health conditions that independently affect labor market exit. The inclusion of these covariates has almost no effect on the findings for males (Table 2, Column 2a). Among females, the estimated coefficients on the lagged diabetes measures remain statistically insignificant (Table 3, Column 2b).

We find, however, that the onset of other chronic conditions has important effects on labor market exit. For both males and females, onset of stroke, psychiatric problems, and lung disease in the previous HRS wave is associated with large, statistically significant increases in the hazard of leaving employment (Columns $2 b$ in Table 2 and $3 b$ in Table 3). Among females, heart problems, arthritis, and hypertension also are associated with an increase in the hazard of leaving employment (Column $3 \mathrm{~b}$ in Table 3). It is not surprising that onset of a range of chronic health conditions play an important role in older individuals' likelihood of leaving employment. 
In Columns 3a-b of Tables 2 and 3, instead of examining the effects of the number of years since diagnosis as a continuous variable, we include dichotomous indicators for having had diabetes for 1-2, 3-5, 6-10, 11-20 and 21 or more years (with no diabetes as the baseline). If the severity of diabetes is related with the number of years since diagnosis, we may observe that some of these indicators are positively associated with leaving employment. However, the findings from models with dichotomous indicators do not offer a clear-cut interpretation since most estimates are statistically insignificant, and the magnitudes do not necessarily get larger for longer lengths of diabetes. Finally, in the last column of Tables 2-3, we show the same model from Columns 3a-b, but this time current diabetes status is used instead of lagged diabetes status. Using current instead of lagged diabetes measures, we see that while diabetes is associated with increased hazard of leaving employment, these associations are not statistically significant for males or females.

In sum, the findings in Tables 2-3 indicate that among males, lagged diabetes with medication is associated with an increased hazard of leaving employment. Among females, diabetes is not associated with leaving employment. The relationship between diabetes and employment among aging individuals appears to be quite different for males vs. females, a finding that is consistent with previous work. We note that among males and females, we fail to reject the null hypothesis of no unobserved heterogeneity in every model. This finding allays our concerns about the assumption of uncorrelated unobserved heterogeneity in these models.

One limitation of the findings shown in Tables 2-3 is that the information on diabetes is self-reported. As a result, we can only examine the effects of diagnosed diabetes, and we can only gauge severity by the respondent's report of medication usage and the number of years since diabetes was diagnosed. In 2006 and 2008, the HRS collected A1C levels from 
respondents, allowing us to consider effects of both diagnosed and undiagnosed diabetes, and consider the effects of severity, on leaving the labor force. Findings based on models that utilize the biomarker information are shown in Tables 4 and 5. Note that for these models, the sample is limited to respondents in our analytic sample who participated in the biomarker collection in 2006 or 2008 and were working for pay at the time biomarker data were collected. The dependent variable in these models is a binary indicator of whether the respondent was still working for pay two years after the biomarker collection (in 2008 or 2010).

In column 1a-b of Table 4, we first show findings from a model in which we consider a lagged, self-reported measure of diabetes, as we did in Tables 2-3. We see that for males, there is no statistically significant association between self-reporting diabetes and subsequent work status two years later, among working HRS respondents (Table 4, column 1a). Among females, however, self-reported diabetes is associated with a large, statistically significant reduction in the probability of working two years later (Table 4, column 1b). In columns $2 \mathrm{a}-\mathrm{b}$ of Table 4 , we consider an indicator that is set equal to 1 if either the respondent reports having diabetes, and/or the respondent's A1C level (collected from biomarkers) indicates that the respondent has diabetes. This measure captures diagnosed cases and undiagnosed cases. The findings are basically unchanged when this measure is used in place of the self-reported measure (Table 4, columns 2a-b). Undiagnosed diabetes, therefore, does not appear to be an important factor in determining employment decisions in this sample.

In the subsequent columns of Table 4, we examine specifications in which we include a continuous measure of A1C (columns $3 \mathrm{a}$ and $3 \mathrm{~b}$ ), dummy variables indicating pre-diabetes and diabetes based on AIC cut-points (columns 4a and 4b), continuous A1C with a control for medication usage (columns 5a and 5b), and, finally, dummy variables indicating pre-diabetes and 
diabetes based on AIC cut-points and an indicator of medication usage (columns 6a and 6b). The goal is to gauge whether including measures of diabetes control (A1C levels) can enrich our understanding of the relationship between diabetes and employment decisions. Among males, all the estimated coefficients are statistically insignificant. Among females, however, AIC level is negatively associated with the likelihood of working two years later; this association is statistically significant at the 0.10 level. Also, having an $\mathrm{A} 1 \mathrm{C}$ level $>=6.5 \%$ has about the same effect on the probability of working two years later as having self-reported diabetes (although this estimated coefficient is not statistically significant).

Finally, in Table 5, we combine the self-reported and the biomarker information to directly test whether diabetes has different effects on being employed two years later if it is controlled vs. uncontrolled (Columns 1-3 of Table 5), or if it diagnosed vs. undiagnosed and controlled vs. uncontrolled (Column 4 of Table 5). In some specifications, we combined the male and female samples since cell sizes become small. Overall, the patters of findings in this table suggests undiagnosed diabetes, as well as diabetes without medication, is not associated with leaving employment, regardless of whether the diabetes is controlled or uncontrolled. This could be simply because undiagnosed diabetes and diabetes without medication are in the earlier stages of the disease. These individuals may not be experiencing symptoms, and they are not spending time managing diabetes (since they are undiagnosed or not using medication). Thus, their labor market status may not be affected.

For diabetes with medication, however, labor market status is affected regardless of whether the disease is under control. In Column 4 of Table 5, we see that diabetes with medication reduces the likelihood of working two years later by about 24 percentage points if it is controlled, and by about 27 percentage points if it is uncontrolled. The "diabetes with 
medication" measure may be capturing a more severe form/stage of the disease. It is also possible that for respondents taking medication, managing diabetes is more time-consuming (e.g., more doctor visits to monitor medication) and therefore has greater effects on labor market outcomes.

\section{Conclusions}

Our findings indicate that diabetes affects leaving employment among men who are approaching retirement age. Among men, the findings are limited to individuals who take medication for diabetes, and we do not find any evidence that diabetes control or undiagnosed diabetes play a role in this relationship. Among females, we find no effect of diabetes on leaving employment in the hazard models. When we focus on the most recent HRS waves during which biomarker data were collected, however, we see that current, self-reported diabetes is associated with a reduction in the likelihood of still being employment in the next HRS wave.

These findings mesh well with those of Rumball-Smith et al. (2014), who utilize data from the $2004 \mathrm{HRS}$ and as well as data from surveys of aging populations in fifteen European countries, to estimate the effect of diabetes on early retirement. The methods, measures, and model specification used are somewhat different from those used in the present study. RumballSmith et al. (2014) find that having diagnosed diabetes increases the risk of leaving the labor force by about 30 percent across countries. This turns out to be similar to what we report in Column 2a of Table 2 - we find that among males, onset of diagnosed diabetes with medication is associated with increased risk of labor market exist of about 39 percent.

In the present study, we find different patterns of findings for men and women. In the hazard models, for example, in which we draw on 1992-2010 HRS waves, we find an association 
between diabetes and leaving employment for males but not for females. This difference may be due to the fact that employed women are more likely to be working part-time than employed men, and thus there is less scope for labor market adjustment due to diabetes onset for women vs. men. In addition, women's occupations and work environments may be more conducive to managing a chronic disease like diabetes. It is not clear why when we limit the sample to the 2006-2010 data, we begin to find effects among women. This may be due to changes in the sample composition when we limit the sample to these later waves.

As a group, results from studies of the effects of diabetes on labor market outcomes are consistent with a recent report by the American Diabetes Association on the economic costs of diabetes; in this report, the authors estimate that about $\$ 69$ billion of the $\$ 245$ bullion total cost of diabetes in 2012 can be attributed to indirect costs, such as absenteeism, reduced productivity, and work disability. Of this $\$ 69$ billion attributed to the indirect costs of diabetes, about $\$ 2.7$ billion results from loss of productivity for those not in the labor force, and \$21.6 billion comes from work-related disability due to diabetes (ADA, 2013). However, this ADA report focuses on costs associated with diagnosed diabetes only - our study suggests that undiagnosed diabetes also affects labor market outcomes as people age. Our results therefore suggest that the total cost of diabetes is probably even higher, and more important to the economy, than these large numbers suggest. 


\section{References}

1. American Diabetes Association (ADA), Economic costs of diabetes in the U.S. in 2012, Diabetes Care, published on-line March 6, 2013.

2. Brown III HS, Pagan JA, Bastida E. 2005. The impact of diabetes on employment: genetic IVs in a bivariate probit. Health Economics 14: 537-544.

3. Buell, C., Kermah, D. \& Davidson, M. B. (2007). Utility of A1C for diabetes screening in the 1999-2004 NHANES Population. Diabetes Care. 30 (9) p. 2233-2235.

4. Centers for Disease Control and Prevention. Diabetes Data \& Trend. Available at: http://www.cdc.gov/diabetes/statistics/prev/national/figageadult.htm. Accessed March 23, 2011.

5. Disney R, Emmerson C, Wakefield M. Ill health and retirement in Britain: A panel databased analysis. Journal of Health Economics 2006; 25: 621-649.

6. Engelgau MM, Geiss LS, Saaddine JB, et al. The evolving diabetes burden in the United States. Ann Intern Med. 2004;140:945-950.

7. Fletcher JM, Richards MR. Diabetes's 'health shock' to schooling and earnings: Increased dropout rates and lower wages and employment in young adults. Health Affairs $2012 ; 31(1): 27-34$

8. Garcia-Gomez P, Jones AM, Rice N. Health effects on labour market exits and entries. Labour Economics 2010; 17(1):62-76.

9. Geiss LS, Rolka DB, Engelgau MM. Elevated blood pressure among U.S. adults with diabetes, 1988-1997. Am J Prev Med. 2002;22(1):42-48. 
10. Ginde, A. A. et al (2008). Value of risk stratification to increase the predictive validity of $\mathrm{HbA} 1 \mathrm{C}$ in screening for undiagnosed diabetes in the US population. Journal of General Internal Medicine. 23 (9) p.1346-1353.

11. Hung WW, et al. Recent trends in chronic disease, impairment and disability among older adults in the United States. BMC Geriatrics 2011; 11(47):1-12.

12. Jenkins, SP. Easy estimation methods for discrete time duration models. Oxford Bulletin of Economics and Statistics 1995, 57, 129-138.

13. Joyce GF, Keeler EB, Shang B, Goldman DP. The lifetime burden of chronic disease among the elderly. Health Affairs 2005.

14. Jones AM, Rice N, Roberts J. Sick of work or too sick to work? Evidence on selfreported health shocks and early retirement from the BHPS. Economic Modeling 2010; 27: 866-880.

15. Latif, E. The impact of diabetes on employment in Canada. Health Economics 2009; 18(5): 577-589.

16. Maahs DM, West NA, Lawrence JM. Mayer-David EJ. 2010. Chapter 1: Epidemiology of Type I Diabetes. Endocrinol Metab Clin North Am. 39(3): 481-497.

17. Miah MS, Wilcox-Gok V. Do the sick retire early? Chronic illness, asset accumulation and early retirement. Applied Economics 2007; 39:1921-1936.

18. Minor T. The effect of diabetes on female labor force decisions: New evidence from the National Health Interview Survey. Health Economics 2011; 20(12): 1468-1486.

19. Minor T. 2013. An investigation into the effect of type I and type II diabetes duration on employment and wages. Economics and Human Biology 11: 534-544. 
20. Mroz TA, Picone G. A multiple state duration model with endogenous treatment. Health, Econometrics and Data Group Working Paper 2011; 11/19.

21. Paez KA, Zhao L, Hwang W. Rising out-of-pocket spending for chronic conditions: a ten-year trend. Health Affairs 2009; 28(1):15-25.

22. Palloni A, Palloni G. Education, earnings, and diabetes. Health Affairs 2012; 31(5):1126.

23. Parekh AK, Barton MB. The challenge of multiple comorbidity for the US health care system. JAMA 2010; 303(13):1303-1304.

24. Rumball-Smith J, Barthhold D, Nandi A, Heyman J. Diabetes associated with early labor force exits: A comparison of sixteen high-income countries. Health Affairs 2014; 33(1): $110-115$

25. Sloan FA, Bethel MA, Ruiz Jr. D, Shea AH, Feinglos MN. The growing burden of diabetes mellitus in the US elderly population. Arch Intern Med 2008; 168(2):192-199.

26. Thorpe KE. The affordable care act lays the groundwork for a national diabetes prevention and treatment strategy. Health Affairs 2012; 31(1):61-66.

27. Tunceli K, Bradley CJ, Nerenz D, Williams L, Keoki P, Pladevall M, Elston J. 2005. The impact of diabetes on employment and work productivity. Diabetes Care 28: 2662-2667.

28. Vijan S, Hayward RA, Langa KM. The impact of diabetes on workforce participation: results from a national household sample. Health Services Research 2004; 39(6):16531669.

29. Vincent GK, Velkoff VA. The next four decades: The older population in the United States, 2010-2050. Current Population Reports P25-1138 May 2010. 
30. Vojta D, De Sa J, Prospect T, Stevens S. Effective interventions for stemming the growing crisis of diabetes and prediabetes: a national payer's perspective. Health Affairs 2012; 31(1):20-26. 
Figure 1: Definitions of labor market exit and censoring

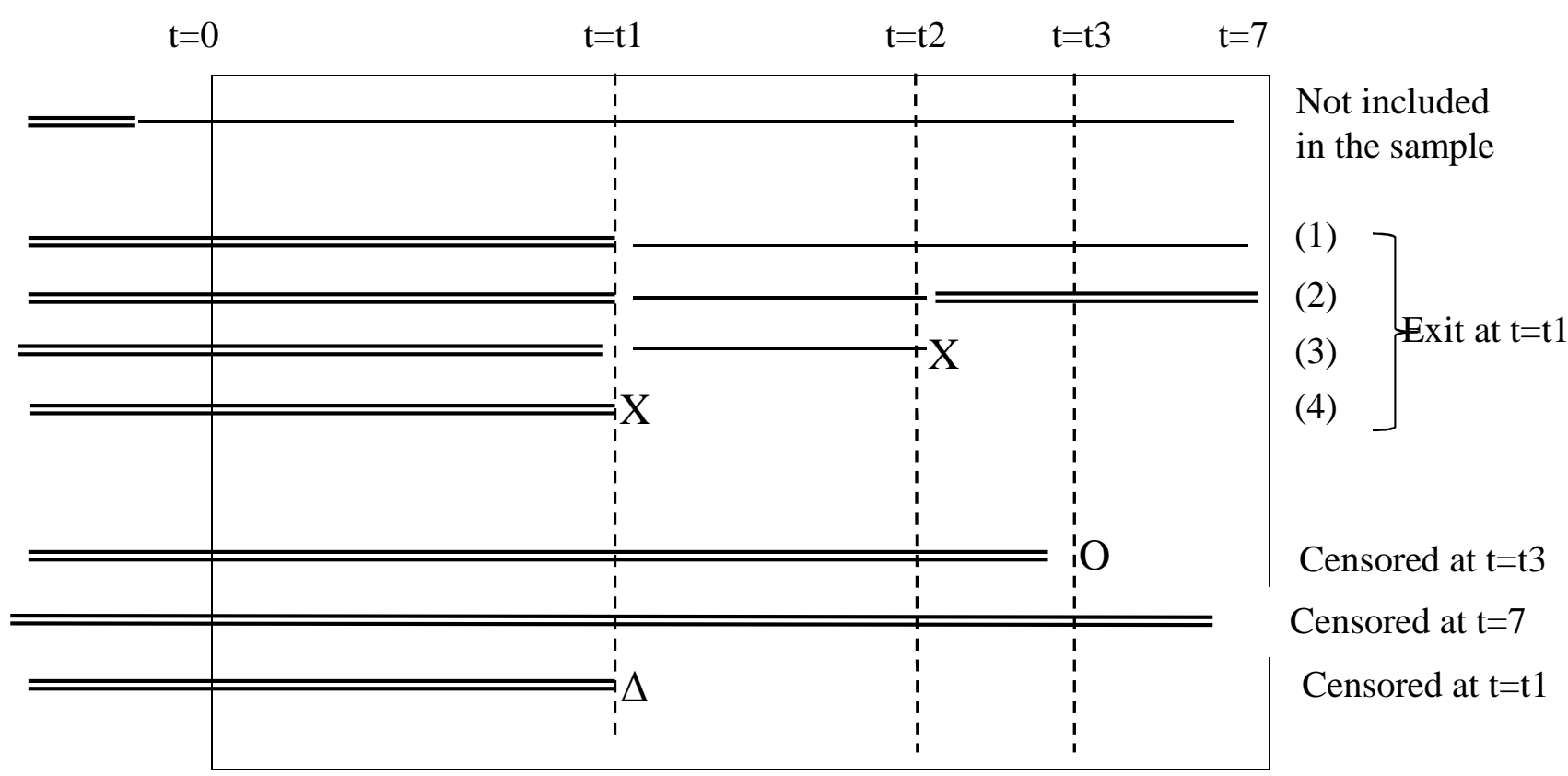

Working for pay

Not working for pay

X: Death

O: Survive at Year 2010

$\Delta$ : non-response before 2010

$\mathrm{t} 1, \mathrm{t} 2$, and $\mathrm{t} 3$ : integers between 1 and 7 
Table 1: List of main health-related variables

\begin{tabular}{|c|c|}
\hline Variable & Description \\
\hline $\begin{array}{l}\text { Diabetes with medication } \\
(\mathrm{t}-1)\end{array}$ & $\begin{array}{l}1 \text { if a respondent reports having diagnosed diabetes and currently } \\
\text { using oral medication and/or insulin shots for treating or } \\
\text { controlling diabetes at t-1,0 otherwise }\end{array}$ \\
\hline $\begin{array}{l}\text { Diabetes without } \\
\text { medication }(\mathrm{t}-1)\end{array}$ & $\begin{array}{l}1 \text { if a respondent reports having diagnosed diabetes but not using } \\
\text { oral medication nor insulin shots for diabetes currently at } t-1,0 \\
\text { otherwise }\end{array}$ \\
\hline $\begin{array}{l}\text { Diabetes (years since } \\
\text { diagnosis at } \mathrm{t} \text { ) }\end{array}$ & Years since diabetes was first diagnosed at $t$ \\
\hline Diabetes $1-2$ years & $1-2$ years since diabetes was first diagnosed at $t$ \\
\hline Diabetes 3-5 years & 3-5 years since diabetes was first diagnosed at $t$ \\
\hline Diabetes 6-10 years & 6-10 years since diabetes was first diagnosed at $t$ \\
\hline Diabetes 11-20 years & $11-20$ years since diabetes was first diagnosed at $t$ \\
\hline Diabetes $21+$ years & 21 or more years since diabetes was first diagnosed at $t$ \\
\hline $\begin{array}{l}\text { Diabetes with medication } \\
(\mathrm{t})\end{array}$ & $\begin{array}{l}1 \text { if a respondent reports having diagnosed diabetes and currently } \\
\text { using oral medication and/or insulin shots for treating or } \\
\text { controlling diabetes at t, } 0 \text { otherwise }\end{array}$ \\
\hline $\begin{array}{l}\text { Diabetes without } \\
\text { medication }(\mathrm{t})\end{array}$ & $\begin{array}{l}1 \text { if a respondent reports having diagnosed diabetes but not using } \\
\text { oral medication nor insulin shots for diabetes currently at t, } 0 \\
\text { otherwise }\end{array}$ \\
\hline Stroke $(\mathrm{t}-1)$ & $\begin{array}{l}1 \text { if a respondent reports that a doctor has ever told him/her that } \\
\text { he/she had a stroke onset at } \mathrm{t}-1,0 \text { otherwise }\end{array}$ \\
\hline $\begin{array}{l}\text { Heart problems } \\
(\mathrm{t}-1)\end{array}$ & $\begin{array}{l}1 \text { if a respondent reports that a doctor has ever told him/her that } \\
\text { he/she has any heart problems at t-1, } 0 \text { otherwise }\end{array}$ \\
\hline Hypertension (t-1) & $\begin{array}{l}1 \text { if a respondent reports that a doctor has ever told him/her that } \\
\text { he/she has high blood pressure or hypertension at } t-1,0 \text { otherwise }\end{array}$ \\
\hline Cancer $(\mathrm{t}-1)$ & $\begin{array}{l}1 \text { if a respondent reports that a doctor has ever told him/her that } \\
\text { he/she had cancer or a malignant tumor, excluding minor skin } \\
\text { cancer at } t-1,0 \text { otherwise }\end{array}$ \\
\hline
\end{tabular}




\begin{tabular}{ll}
\hline Arthritis (t-1) & $\begin{array}{l}1 \text { if a respondent reports that a doctor has ever told him/her that } \\
\text { he/she has any arthritis or rheumatism at } \mathrm{t}-1,0 \text { otherwise }\end{array}$ \\
\hline Psychiatric problem (t-1) & $\begin{array}{l}1 \text { if a respondent reports that a doctor has ever told him/her that } \\
\text { he/she has any emotional, nervous, or psychiatric problems at } \mathrm{t}-1, \\
0 \text { otherwise }\end{array}$ \\
\hline Lung disease (t-1) & $\begin{array}{l}1 \text { if a respondent reports that a doctor has ever told him/her that } \\
\text { he/she had chronic lung disease at } \mathrm{t}-1,0 \text { otherwise }\end{array}$ \\
\hline BMI (t-1) & Continuous variable with body mass index at t-1 \\
\hline BMI square (t-1) & Continuous variable with squared body mass index at t-1 \\
\hline
\end{tabular}


Table 2: Effect of diabetes on leaving employment, Males

\begin{tabular}{|c|c|c|c|c|}
\hline Column & $1 \mathrm{a}$ & $2 \mathrm{a}$ & $3 a$ & $4 a$ \\
\hline \multirow{2}{*}{$\begin{array}{l}\text { Diabetes without } \\
\text { medication }(\mathrm{t}-1)\end{array}$} & 1.26 & 1.23 & 1.13 & \\
\hline & $(0.23)$ & $(0.22)$ & $(0.29)$ & \\
\hline \multirow{2}{*}{$\begin{array}{l}\text { Diabetes with medication } \\
(\mathrm{t}-1)\end{array}$} & $1.40^{*}$ & $1.39 *$ & 1.25 & \\
\hline & $(0.19)$ & $(0.19)$ & $(0.28)$ & \\
\hline \multirow{2}{*}{$\begin{array}{l}\text { Diabetes without } \\
\text { medication } \\
(\mathrm{t})\end{array}$} & & & & 1.13 \\
\hline & & & & $(0.27)$ \\
\hline \multirow{2}{*}{$\begin{array}{l}\text { Diabetes with medication } \\
(\mathrm{t})\end{array}$} & & & & 1.43 \\
\hline & & & & $(0.29)$ \\
\hline \multirow{2}{*}{$\begin{array}{c}\text { Diabetes } \\
\text { (years since diagnosis at } \\
\mathrm{t} \text { ) }\end{array}$} & 0.99 & 0.99 & & \\
\hline & $(0.01)$ & $(0.01)$ & & \\
\hline \multirow{2}{*}{ Diabetes 1-2 years } & & & 1.01 & 0.80 \\
\hline & & & $(0.19)$ & $(0.20)$ \\
\hline \multirow[t]{2}{*}{ Diabetes 3-5 years } & & & 1.13 & 1.03 \\
\hline & & & $(0.27)$ & $(0.23)$ \\
\hline \multirow[t]{2}{*}{ Diabetes 6-10 years } & & & 0.87 & 0.80 \\
\hline & & & $(0.22)$ & $(0.19)$ \\
\hline \multirow[t]{2}{*}{ Diabetes $11-20$ years } & & & 1.32 & 1.18 \\
\hline & & & $(0.33)$ & $(0.27)$ \\
\hline \multirow[t]{2}{*}{ Diabetes $21+$ years } & & & 0.76 & 0.68 \\
\hline & & & $(0.28)$ & $(0.25)$ \\
\hline \multirow[t]{2}{*}{ Stroke $(\mathrm{t}-1)$} & & $1.79 * *$ & $1.80 * *$ & \\
\hline & & $(0.29)$ & $(0.29)$ & \\
\hline \multirow[t]{2}{*}{ Heart problems $(\mathrm{t}-1)$} & & 1.14 & 1.14 & \\
\hline & & $(0.10)$ & $(0.10)$ & \\
\hline \multirow[t]{2}{*}{ Hypertension (t-1) } & & 1.13 & 1.13 & \\
\hline & & $(0.08)$ & $(0.07)$ & \\
\hline \multirow[t]{2}{*}{ Cancer (t-1) } & & 1.16 & 1.16 & \\
\hline & & $(0.14)$ & $(0.14)$ & \\
\hline \multirow[t]{2}{*}{ Arthritis (t-1) } & & 1.04 & 1.04 & \\
\hline & & $(0.07)$ & $(0.07)$ & \\
\hline \multirow[t]{2}{*}{ Psychiatric problem (t-1) } & & $1.24 *$ & $1.25^{*}$ & \\
\hline & & $(0.13)$ & $(0.13)$ & \\
\hline \multirow{2}{*}{$\begin{array}{l}\text { Lung disease } \\
\qquad(\mathrm{t}-1)\end{array}$} & & $1.36^{*}$ & $1.35^{*}$ & \\
\hline & & $(0.16)$ & $(0.16)$ & \\
\hline BMI (t-1) & & $0.88^{*}$ & $0.88 * *$ & \\
\hline
\end{tabular}




\begin{tabular}{|l|l|c|c|c|}
\hline & & $(0.04)$ & $(0.04)$ & \\
\hline BMI square (t-1) & & $1.002^{*}$ & $1.002^{*}$ & \\
\hline & & $(0.001)$ & $(0.001)$ & \\
\hline p-value (LR test : rho=0) & 0.491 & 0.486 & 0.493 & 0.491 \\
\hline $\mathrm{N}$ & \multicolumn{4}{|c|}{2,570} \\
\hline Observations & \multicolumn{4}{|c|}{9,270} \\
\hline
\end{tabular}

Notes: Table shows estimated hazard ratios and standard errors associated with selected covariates based on a random effects discrete time duration model. Standard errors are in parentheses. Other covariates included in all of the models but not shown in table are: education (less than high school (baseline), high school graduate, some college, college or more), race (non-Latino white (baseline), African-American, Latino, Other races/ethnicity), log of household income, lag of marital status (binary: married=1, otherwise $=0$ ), spouse education (less than high school (baseline), high school graduate, some college, college or more), lag of spouse working status (binary: working for pay $=1$, otherwise $=0$ ), type of industry in which a respondent currently is working (12 industry dummies and not specified), period dummies (observation from $\mathrm{t}=1$ (baseline), 2, 3, 4, 5, 6, and 7), and cohort dummies (becoming 53 years old at wave 1 (baseline), 2, 3, 4, 5, 6, 7, 8, and 9). Lag of BMI and BMI squared were included in models (2a) and (3a) only. **p<0.01, * p<0.05. 
Table 3: Effect of diabetes on leaving employment, Females

\begin{tabular}{|c|c|c|c|c|}
\hline \multirow[b]{2}{*}{ Column } & Females & & & \\
\hline & $1 b$ & $2 \mathrm{~b}$ & $3 b$ & $4 \mathrm{~b}$ \\
\hline \multirow{2}{*}{$\begin{array}{l}\text { Diabetes without } \\
\text { medication }(\mathrm{t}-1)\end{array}$} & 0.94 & 0.91 & 0.65 & \\
\hline & $(0.21)$ & $(0.19)$ & $(0.19)$ & \\
\hline \multirow{2}{*}{$\begin{array}{l}\text { Diabetes with medication } \\
\qquad(\mathrm{t}-1)\end{array}$} & 1.13 & 1.01 & 0.73 & \\
\hline & $(0.17)$ & $(0.14)$ & $(0.18)$ & \\
\hline \multirow{2}{*}{$\begin{array}{l}\text { Diabetes without } \\
\text { medication }(\mathrm{t})\end{array}$} & & & & 0.84 \\
\hline & & & & $(0.23)$ \\
\hline \multirow{2}{*}{$\begin{array}{c}\text { Diabetes with medication } \\
(\mathrm{t})\end{array}$} & & & & 1.14 \\
\hline & & & & $(0.29)$ \\
\hline \multirow{2}{*}{$\begin{array}{c}\text { Diabetes } \\
\text { (years since diagnosis at } \\
\mathrm{t} \text { ) }\end{array}$} & 1.01 & 1.01 & & \\
\hline & $(0.01)$ & $(0.01)$ & & \\
\hline \multirow[t]{2}{*}{ Diabetes $1-2$ years } & & & $1.52 *$ & 1.51 \\
\hline & & & $(0.28)$ & $(0.42)$ \\
\hline \multirow[t]{2}{*}{ Diabetes 3-5 years } & & & 1.54 & 1.23 \\
\hline & & & $(0.43)$ & $(0.34)$ \\
\hline \multirow[t]{2}{*}{ Diabetes 6-10 years } & & & 1.46 & 1.15 \\
\hline & & & $(0.41)$ & $(0.32)$ \\
\hline \multirow[t]{2}{*}{ Diabetes $11-20$ years } & & & 1.61 & 1.32 \\
\hline & & & $(0.47)$ & $(0.38)$ \\
\hline \multirow[t]{2}{*}{ Diabetes $21+$ years } & & & 1.58 & 1.58 \\
\hline & & & $(0.48)$ & $(0.51)$ \\
\hline \multirow[t]{2}{*}{ Stroke $(\mathrm{t}-1)$} & & $1.62 *$ & $1.63 * *$ & \\
\hline & & $(0.30)$ & $(0.30)$ & \\
\hline \multirow[t]{2}{*}{ Heart problems (t-1) } & & $1.26^{*}$ & $1.27 *$ & \\
\hline & & $(0.13)$ & $(0.13)$ & \\
\hline \multirow[t]{2}{*}{ Hypertension (t-1) } & & $1.16^{*}$ & $1.15^{*}$ & \\
\hline & & $(0.08)$ & $(0.08)$ & \\
\hline \multirow[t]{2}{*}{ Cancer (t-1) } & & 0.98 & 0.98 & \\
\hline & & $(0.11)$ & $(0.11)$ & \\
\hline \multirow[t]{2}{*}{ Arthritis (t-1) } & & $1.25 * *$ & $1.25 * *$ & \\
\hline & & $(0.08)$ & $(0.08)$ & \\
\hline \multirow[t]{2}{*}{ Psychiatric problem (t-1) } & & $1.42 * *$ & $1.43 * *$ & \\
\hline & & $(0.12)$ & $(0.12)$ & \\
\hline \multirow{2}{*}{$\begin{array}{l}\text { Lung disease } \\
\qquad(\mathrm{t}-1)\end{array}$} & & $1.32 *$ & $1.32 *$ & \\
\hline & & $(0.15)$ & $(0.15)$ & \\
\hline \multirow[t]{2}{*}{ BMI (t-1) } & & 0.96 & 0.95 & \\
\hline & & $(0.03)$ & $(0.03)$ & \\
\hline BMI square (t-1) & & 1.00 & 1.001 & \\
\hline
\end{tabular}




\begin{tabular}{|l|c|c|c|c|}
\hline & & $(0.001)$ & $(0.001)$ & \\
\hline $\mathrm{p}$-value (LR test $:$ rho=0) & 0.257 & 0.358 & 0.308 & 0.183 \\
\hline $\mathrm{N}$ & \multicolumn{4}{|c|}{2,756} \\
\hline Observations & \multicolumn{4}{|c|}{9,350} \\
\hline
\end{tabular}

Notes: Table shows estimated hazard ratios and standard errors associated with selected covariates based on a random effects discrete time duration model. Standard errors are in parentheses. Other covariates included in all of the models but not shown in table are: education (less than high school (baseline), high school graduate, some college, college or more), race (non-Latino white (baseline), African-American, Latino, Other races/ethnicity), log of household income, lag of marital status (binary: married=1, otherwise $=0$ ), spouse education (less than high school (baseline), high school graduate, some college, college or more), lag of spouse working status (binary: working for pay $=1$, otherwise $=0$ ), type of industry in which a respondent currently is working (12 industry dummies and not specified), period dummies (observation from $\mathrm{t}=1$ (baseline), 2, 3, 4, 5, 6, and 7), and cohort dummies (becoming 55/56 years old at wave 1 (baseline), 2, 3, 4, 5, 6, 7, 8 and 9). Lag of BMI and BMI squared were included models ( $2 b$ ) and ( $3 b$ ) only. $* * p<0.01, * p<0.05$. 
Table 4: Effects of diagnosed and undiagnosed diabetes on probability of working two years later

\begin{tabular}{|c|c|c|c|c|c|c|c|c|c|c|c|c|}
\hline \multirow[t]{2}{*}{ Column } & \multicolumn{6}{|c|}{ Males } & \multicolumn{6}{|c|}{ Females } \\
\hline & $1 \mathrm{a}$ & $2 \mathrm{a}$ & $3 a$ & $4 \mathrm{a}$ & $5 a$ & $6 a$ & $1 \mathrm{~b}$ & $2 b$ & $3 b$ & $4 \mathrm{~b}$ & $5 b$ & $6 b$ \\
\hline \multirow[t]{2}{*}{ Self-reported diabetes } & -0.10 & & & & & & $-0.34 * *$ & & & & & \\
\hline & $(0.14)$ & & & & & & $(0.13)$ & & & & & \\
\hline \multirow{2}{*}{$\begin{array}{l}\text { Self-reported diabetes } \\
\text { and/or A1C indicates } \\
\text { diabetes }\end{array}$} & & -0.15 & & & & & & $-0.29 *$ & & & & \\
\hline & & $(0.13)$ & & & & & & $(0.13)$ & & & & \\
\hline \multirow[t]{2}{*}{ A1C level } & & & 0.01 & & 0.06 & & & & $-0.11 *$ & & -0.06 & \\
\hline & & & $(0.05)$ & & $(0.06)$ & & & & $(0.05)$ & & $(0.06)$ & \\
\hline \multirow[t]{2}{*}{$5.7 \%<=\mathrm{A} 1 \mathrm{C}<6.5 \%$} & & & & 0.12 & & 0.16 & & & & -0.18 & & -0.13 \\
\hline & & & & $(0.13)$ & & $(0.13)$ & & & & $(0.11)$ & & $(0.11)$ \\
\hline \multirow[t]{2}{*}{$\mathrm{A} 1 \mathrm{C}>=6.5 \%$} & & & & -0.14 & & -0.01 & & & & -0.25 & & 0.02 \\
\hline & & & & $(0.16)$ & & $(0.21)$ & & & & $(0.17)$ & & $(0.22)$ \\
\hline \multirow{2}{*}{$\begin{array}{l}\text { Taking medication for } \\
\text { diabetes }\end{array}$} & & & & & -0.27 & -0.18 & & & & & -0.27 & $-0.36^{*}$ \\
\hline & & & & & $(0.17)$ & $(0.19)$ & & & & & $(0.17)$ & $(0.17)$ \\
\hline $\mathrm{N}$ & \multicolumn{6}{|c|}{912} & \multicolumn{6}{|c|}{$\frac{1}{1,057}$} \\
\hline
\end{tabular}

Notes: Table shows estimated marginal effects and standard errors associated with selected covariates based on a probit model. Standard errors are in parentheses. Dependent variable is a binary indicator of currently (2008 and 2010) working for payment 2 years after the diabetes/A1C measurement (2006 and 2008). The sample is the sample used in Tables 2-3 limited to those who had A1C measure in 2006 or 2008. Other covariates included in the models but not shown in table are: education (less than high school (baseline), high school graduate, some college, college or more), race (non-Latino white (baseline), African-American, Latino, Other races/ethnicity), log of household income, lag of marital status (binary: married=1, otherwise $=0$ ), lag of spouse education (less than high school (baseline), high school graduate, some college, college or more), lag of spouse working status (binary: working for pay=1, otherwise=0), type of industry in which a respondent currently is working (12 industry dummies and not specified), period dummies (observation from 2006 (baseline) and 2008), and dummy indicators for each age (age 57/58 is the baseline). ${ }^{*} \mathrm{p}<0.05,+\mathrm{p}<0.1$. 
Table 5: Effects of diagnosed and undiagnosed diabetes on probability of working two years later

\begin{tabular}{|c|c|c|c|c|}
\hline & Males & Females & Both & Both \\
\hline \multirow{2}{*}{$\begin{array}{l}\text { Uncontrolled diabetes (self-reported diabetes } \\
\qquad \& \mathrm{~A} 1 \mathrm{C}>=6.5) \\
(\mathrm{t}-1)\end{array}$} & -0.19 & -0.22 & $-0.20+$ & \\
\hline & $(0.15)$ & $(0.17)$ & $(0.11)$ & \\
\hline \multirow{2}{*}{$\begin{array}{l}\text { Controlled diabetes (self-reported diabetes } \\
\qquad \& \mathrm{~A} 1 \mathrm{C}<6.5) \\
(\mathrm{t}-1)\end{array}$} & -0.08 & $-0.37 *$ & $-0.22+$ & \\
\hline & $(0.19)$ & $(0.18)$ & $(0.13)$ & \\
\hline $\begin{array}{l}\text { Undiagnosed diabetes (self-report }=\text { no and } \\
\qquad A 1 C>=6.5 \text { ) }\end{array}$ & & & & $\begin{array}{l}-0.13 \\
(0.22) \\
\end{array}$ \\
\hline $\begin{array}{l}\text { Diagnosed diabetes without medication and } \\
\text { controlled }(\mathrm{A} 1 \mathrm{C}<6.5)\end{array}$ & & & & $\begin{array}{l}-0.16 \\
(0.24)\end{array}$ \\
\hline $\begin{array}{l}\text { Diagnosed diabetes without medication and } \\
\text { uncontrolled }(\mathrm{A} 1 \mathrm{C}>=6.5)\end{array}$ & & & & $\begin{array}{c}0.13 \\
(0.36)\end{array}$ \\
\hline $\begin{array}{l}\text { Diagnosed diabetes with medication and } \\
\text { controlled }(\mathrm{A} 1 \mathrm{C}<6.5)\end{array}$ & & & & $\begin{array}{r}-0.24+ \\
(0.15)\end{array}$ \\
\hline $\begin{array}{c}\text { Diagnosed diabetes with medication and } \\
\text { uncontrolled }(\mathrm{A} 1 \mathrm{C}>=6.5)\end{array}$ & & & & $\begin{array}{l}-0.27 * \\
(0.13)\end{array}$ \\
\hline $\mathrm{N}$ & 912 & 1,057 & 1,969 & 1,969 \\
\hline
\end{tabular}

Notes: Table shows estimated marginal effects and standard errors associated with selected covariates based on a probit model. Standard errors are in parentheses. Dependent variable is a binary indicator of currently (2008 and 2010) working for payment 2 years after the diabetes/A1C measurement (2006 and 2008). The sample used is the same sample used in Tables 2-3 limited to those who had A1C measure in 2006 or 2008. Other covariates included in the models but not shown in table are: education (less than high school (baseline), high school graduate, some college, college or more), race (non-Latino whites (baseline), African-American, Latino, Other races/ethnicities), log of household income, lag of marital status (binary: married $=1$, otherwise $=0$ ), lag of spouse education (less than high school (baseline), high school graduate, some college, college or more), lag of spouse working status (binary: working for pay $=1$, otherwise $=0$ ), type of industry at which a respondent currently is working ( 12 industry dummies and not specified), period dummies (observation from 2006 (baseline) and 2008), and dummy indicators for each age (age $57 / 57$ is the baseline). $* \mathrm{p}<0.05,+\mathrm{p}<0.1$. 
Appendix Table 1: Number of individuals who turn 55-56 years old $(t=0)$ by HRS wave

\begin{tabular}{ccccccc}
\hline & \multicolumn{3}{c}{ Male } & \multicolumn{3}{c}{ Female } \\
\cline { 2 - 7 } & $\begin{array}{c}\text { Working for } \\
\text { pay }\end{array}$ & $\begin{array}{c}\text { Not working } \\
\text { for pay }\end{array}$ & Total & $\begin{array}{c}\text { Working for } \\
\text { pay }\end{array}$ & $\begin{array}{c}\text { Not working } \\
\text { for pay }\end{array}$ & Total \\
\hline 1992 & 709 & $186(1)$ & 895 & 639 & $391(1)$ & 1,030 \\
1994 & 585 & 166 & 751 & 515 & $312(1)$ & 827 \\
1996 & 604 & $147(3)$ & 751 & 573 & $368(5)$ & 941 \\
1998 & 372 & 88 & 460 & 490 & $224(4)$ & 714 \\
2000 & 267 & 50 & 317 & 332 & 188 & 520 \\
2002 & 305 & $80(2)$ & 385 & 393 & $200(1)$ & 593 \\
2004 & 380 & $106(2)$ & 486 & 427 & $191(2)$ & 618 \\
2006 & 352 & $100(1)$ & 452 & 375 & 202 & 577 \\
2008 & 342 & 104 & 446 & 398 & 167 & 655 \\
2010 & 30 & 9 & 39 & 91 & 52 & 143 \\
\hline Sum & 3,946 & $1,036(9)$ & 4,982 & 4,233 & $2,295(14)$ & 6,528 \\
\hline
\end{tabular}

Notes: Numbers in parentheses are those who have missing values for working for payment. They are included in notworking for pay group in this Table. 
Appendix Table 2: Diabetes status of analysis sample used in Tables 4 and 5

\begin{tabular}{|c|c|c|c|}
\hline Diabetes Category & Number of males & Number of females & $\begin{array}{c}\text { Total number of } \\
\text { respondents in sample }\end{array}$ \\
\hline $\begin{array}{l}\text { No diabetes }(\text { self- } \\
\text { report=no biomarker }= \\
\text { no) }\end{array}$ & 735 & 883 & 1,618 \\
\hline $\begin{array}{l}\text { Undiagnosed diabetes } \\
\text { (self-report = no } \\
\text { biomarker }=\text { yes })\end{array}$ & 30 & 21 & 51 \\
\hline $\begin{array}{l}\text { Diagnosed diabetes } \\
\text { without medication and } \\
\text { controlled (self-report \& } \\
\text { A1C level in acceptable } \\
\text { range) }\end{array}$ & 22 & 19 & 41 \\
\hline $\begin{array}{l}\text { Diagnosed diabetes } \\
\text { without medication and } \\
\text { uncontrolled (self-report } \\
\& \text { elevated A1C level) }\end{array}$ & 12 & 8 & 20 \\
\hline $\begin{array}{l}\text { Diagnosed diabetes with } \\
\text { medication and } \\
\text { controlled (self-report \& } \\
\text { A1C level in acceptable } \\
\text { range) }\end{array}$ & 47 & 56 & 103 \\
\hline $\begin{array}{l}\text { Diagnosed diabetes with } \\
\text { medication and } \\
\text { uncontrolled (self-report } \\
\& \text { elevated A1C level) }\end{array}$ & 66 & 70 & 136 \\
\hline Total & 912 & 1,057 & 1,969 \\
\hline
\end{tabular}

Notes: The table is based on the same sample used in Table 2 and 3 limited to those who had A1C measure in 2006 or 2008. 


\begin{tabular}{|l|c|c|c|c|c|c|}
\hline \multicolumn{7}{|c|}{ Appendix Table 3: Diabetes status over time } \\
\hline $\mathrm{t}$ & \multicolumn{7}{|c|}{ Males } & & \\
\cline { 2 - 7 } & Diabetes & $\begin{array}{c}\text { w/o } \\
\text { medication }\end{array}$ & $\begin{array}{c}\text { w/ } \\
\text { medication }\end{array}$ & $\begin{array}{c}\text { No } \\
\text { Diabetes }\end{array}$ & Total & $\begin{array}{c}\text { \% with } \\
\text { diabetes }\end{array}$ \\
\hline 0 & 263 & 67 & 196 & 2,336 & 2,599 & 10.1 \\
\hline 1 & 307 & 69 & 238 & 2,263 & 2,570 & 11.9 \\
\hline 2 & 310 & 77 & 233 & 1,787 & 2,097 & 14.8 \\
\hline 3 & 265 & 57 & 208 & 1,436 & 1,701 & 15.6 \\
\hline 4 & 206 & 36 & 170 & 1,080 & 1,286 & 16.0 \\
\hline 5 & 169 & 32 & 137 & 753 & 922 & 18.3 \\
\hline 6 & 142 & 23 & 119 & 552 & 694 & 20.5 \\
\hline $\mathrm{t}$ & \multicolumn{7}{|c|}{ Females } & No & Total & $\%$ with \\
\cline { 2 - 8 } & Diabetes & w/o & w/ & Diabetes \\
\hline 0 & 244 & 63 & 181 & 2,598 & 2,842 & 8.5 \\
\hline 1 & 278 & 63 & 215 & 2,478 & 2,756 & 10.1 \\
\hline 2 & 235 & 47 & 188 & 1,934 & 2,169 & 10.8 \\
\hline 3 & 191 & 46 & 145 & 1,515 & 1,706 & 11.2 \\
\hline 4 & 148 & 32 & 116 & 1,123 & 1,271 & 11.6 \\
\hline 5 & 108 & 22 & 86 & 753 & 861 & 12.5 \\
\hline 6 & 82 & 21 & 61 & 505 & 587 & 14.0 \\
\hline
\end{tabular}

Notes: The sample is based on the same sample used in Table 2 and Table 3 limited to those who had A1C measure in 2006 or 2008. 
Appendix Table 4: Estimates of impact diabetes on leaving employment - All estimates

\begin{tabular}{|c|c|c|c|c|}
\hline & Male & & Female & \\
\hline & $\begin{array}{l}\text { Estimates } \\
(3 \mathrm{a})\end{array}$ & $\begin{array}{l}\text { Standard } \\
\text { error }\end{array}$ & $\begin{array}{l}\text { Estimates } \\
(3 \mathrm{~b})\end{array}$ & $\begin{array}{l}\text { Standard } \\
\text { error }\end{array}$ \\
\hline \multicolumn{5}{|l|}{ Health conditions } \\
\hline Diabetes without Medication (t-1) & 1.13 & 0.29 & 0.65 & 0.19 \\
\hline Diabetes with medication $(\mathrm{t}-1)$ & 1.25 & 0.28 & 0.73 & 0.18 \\
\hline Diabetes 1-2 years & 1.01 & 0.19 & $1.52 *$ & 0.28 \\
\hline Diabetes 3-5 years & 1.13 & 0.27 & 1.54 & 0.43 \\
\hline Diabetes 6-10 years & 0.87 & 0.22 & 1.46 & 0.41 \\
\hline Diabetes $11-20$ years & 1.32 & 0.33 & 1.61 & 0.47 \\
\hline Diabetes $21+$ years & 0.76 & 0.28 & 1.58 & 0.48 \\
\hline Stroke $(\mathrm{t}-1)$ & $1.79 * *$ & 0.29 & $1.63 *$ & 0.31 \\
\hline Heart disease $(\mathrm{t}-1)$ & 1.14 & 0.10 & $1.27 *$ & 0.13 \\
\hline Cancer $(\mathrm{t}-1)$ & 1.16 & 0.14 & 0.98 & 0.11 \\
\hline Hypertension (t-1) & 1.13 & 0.07 & $1.15^{*}$ & 0.08 \\
\hline Arthritis (t-1) & 1.04 & 0.07 & $1.25 * *$ & 0.08 \\
\hline Psychiatric problems (t-1) & $1.25 *$ & 0.13 & $1.43 * *$ & 0.12 \\
\hline Lung disease $(\mathrm{t}-1)$ & $1.35 *$ & 0.16 & $1.32 *$ & 0.15 \\
\hline BMI $(\mathrm{t}-1)$ & $0.88 * *$ & 0.04 & 0.95 & 0.03 \\
\hline BMI square $(\mathrm{t}-1)$ & $1.002 *$ & 0.001 & 1.001 & 0.001 \\
\hline \multicolumn{5}{|l|}{ Race/ethnicity } \\
\hline African-American & 0.93 & 0.10 & 1.11 & 0.10 \\
\hline Latino & 0.92 & 0.12 & $1.51 * *$ & 0.19 \\
\hline Other races & 0.93 & 0.20 & 1.10 & 0.23 \\
\hline Married & 0.89 & 0.09 & $1.51 * *$ & 0.17 \\
\hline \multicolumn{5}{|l|}{ Spouse education } \\
\hline High school graduate & 1.06 & 0.11 & 1.17 & 0.16 \\
\hline Some college & 1.03 & 0.11 & 1.03 & 0.14 \\
\hline College and more & 1.03 & 0.13 & 1.07 & 0.16 \\
\hline Spouse working for pay $(\mathrm{t}-1)$ & $0.82 * *$ & 0.06 & $0.78 * *$ & 0.07 \\
\hline \multicolumn{5}{|l|}{ Education } \\
\hline High school graduate & 0.94 & 0.09 & 0.88 & 0.08 \\
\hline Some college & 0.89 & 0.09 & $0.78 *$ & 0.08 \\
\hline College and more & $0.66^{* *}$ & 0.08 & $0.69 * *$ & 0.08 \\
\hline
\end{tabular}




\begin{tabular}{|c|c|c|c|c|}
\hline Log of total income $(\mathrm{t}-1)$ & 0.98 & 0.04 & 1.09 & 0.05 \\
\hline \multicolumn{5}{|l|}{$\begin{array}{l}\text { Job industry (baseline: } \\
\text { Agriculture/Forest/Fish) (t-1) }\end{array}$} \\
\hline $\begin{array}{l}\text { Does not have job/does not report } \\
\text { industry }\end{array}$ & 0.95 & 0.21 & 0.60 & 0.21 \\
\hline Mining and Construction & $1.55^{*}$ & 0.33 & 1.55 & 0.66 \\
\hline Manufacturing & $1.93 * *$ & 0.35 & 1.50 & 0.52 \\
\hline Transportation & $2.20 * *$ & 0.44 & 1.37 & 0.52 \\
\hline Wholesale & $1.98 * *$ & 0.43 & 1.06 & 0.45 \\
\hline Retail & 1.25 & 0.30 & 1.19 & 0.41 \\
\hline Finance/Insurance/Real Estate & 1.31 & 0.30 & 0.96 & 0.35 \\
\hline Business/Repair Services & 1.48 & 0.36 & 1.16 & 0.42 \\
\hline Personal services & 1.27 & 0.29 & 1.25 & 0.44 \\
\hline Entertainment/Recreation & $1.85^{*}$ & 0.57 & 0.95 & 0.42 \\
\hline Professional/Related services & 1.49 & 0.54 & 1.24 & 0.42 \\
\hline Public Administration & $2.24 * *$ & 0.52 & 1.39 & 0.52 \\
\hline Entering at wave 2 & 0.95 & 0.12 & 0.87 & 0.13 \\
\hline Entering at wave 3 & 0.97 & 0.09 & 0.91 & 0.09 \\
\hline Entering at wave 4 & 1.05 & 0.11 & 0.95 & 0.10 \\
\hline Entering at wave 5 & $1.35 *$ & 0.16 & 1.08 & 0.13 \\
\hline Entering at wave 6 & 1.11 & 0.15 & 1.06 & 0.13 \\
\hline Entering at wave 7 & 1.29 & 0.18 & 1.14 & 0.15 \\
\hline Entering at wave 8 & $1.83 * *$ & 0.29 & $1.37 *$ & 0.21 \\
\hline Entering at wave $9-10$ & $2.38 * *$ & 0.46 & 1.41 & 0.27 \\
\hline $\mathrm{T}=2$ & 1.15 & 0.12 & 1.12 & 0.11 \\
\hline $\mathrm{T}=3$ & $1.71 * *$ & 0.18 & $1.34 *$ & 0.17 \\
\hline $\mathrm{T}=4$ & $2.52 * *$ & 0.27 & $1.98 * *$ & 0.33 \\
\hline $\mathrm{T}=5$ & $2.19 * *$ & 0.27 & $1.96 * *$ & 0.43 \\
\hline $\mathrm{T}=6$ & $2.56^{* *}$ & 0.34 & $2.23 * *$ & 0.60 \\
\hline Constant & 0.54 & 0.48 & $0.05 * *$ & 0.04 \\
\hline
\end{tabular}

Notes: Table shows full regression results for models shown in Column $3 \mathrm{a}$ of Table 2 and Column $3 \mathrm{~b}$ of Table 3. 